\title{
Bone morphogenetic proteins: A strategic review
}

\author{
Anish Manocha',*, Surinder Sachdeva², Shalu Chandna Bathla ${ }^{3}$, Sharuti Manocha ${ }^{4}$, Anika Daing ${ }^{5}$ \\ ${ }^{1}$ Reader, ${ }^{2}$ Professor \& HOD, ${ }^{3}$ Professor, ${ }^{4}$ Senior Lecturer, ${ }^{5}$ Assistant Professor, ${ }^{\mathbf{1 - 3 , 5}}$ Dept. of Periodontics, ${ }^{4}$ Dept. of \\ Prosthodontics, ${ }^{1-3}$ M. M. College of Dental Sciences \& Research, Mullana, Haryana, ${ }^{4}$ National Dental College and Hospital, Dera \\ Bassi, Punjab, ${ }^{5}$ Jamia Millia Islamia, New Delhi, India
}

*Corresponding Author:

Email: dranishmanocha@hotmail.com

\begin{abstract}
Bone morphogenetic proteins (BMPs) are the cytokines which play a pivotal role in embryonic patterning and initial skeletal development and also have a potent effect on bone and cartilage growth. BMPs have promising prospects for repair of bone and cartilage, therapeutic utility in orthopaedic and dento-alveolar reconstruction,working as powerful bone-inducing components in diverse tissue-engineering products. Considering the increasing amount of work in the field of BMPs, there are prospects of a brilliant future in the field of regenerative medicine of bone and cartilage with the use of BMPs. This review focuses on its historical background, structure, functions, mechanism of the bone formation, carriers and its clinical applications.
\end{abstract}

Keywords: Bone morphogenetic proteins, BMP's, Autoinduction, Bone formation, Signalling molecules, Transforming growth factor $\beta$, Bone induction cascade.

\section{Introduction}

Bone morphogenetic proteins (BMPs) are multifunctional growth factors that are structurally related to transforming growth factor beta (TGF - $\beta$ ) superfamily and activins, andare responsible formigration,proliferation and differentiationof several cell types. ${ }^{1}$

Bone morphogenic proteins are well known for their potential in the autoinduction of bone and cartilage. They represent a unique set of differentiation factors that induce new bone formation where they are implanted instead of changing the growth rate of pre-existing bone. Given that BMP's induce new bone growth, in vivo, promote the recruitment and growth of osteoblast progenitor, and maintain the expression of osteoblast phenotypes in cultures, it is conceivable that providing an optimal dose of a BMP in the circulation may help trigger the osteogenic responses, as an endocrine signal, and restore the loss of bone mass and quality.

BMPs have great potential for repair of bone and cartilage, working as potent bone-inducing components in diverse tissue-engineering products. Many substances can be used as carriers for the delivery of BMP's such as Synthetic polymers, natural origin polymers, inorganic materials and composites. Carriers may range from nano-particles to complicate threedimensional (3D) scaffolds, membranes for tissueguided regeneration, biometricsurfaces and smart thermosensitive hydrogels.

\section{Historical Background}

Urist in 1965 was the first one to identify the BMP's when it was found out that demineralized bone matrix implanted in ectopic sites in rats induced the bone formation. The triphasic theory of calcification was put to test and Urist and co-workers discovered that control samples of untreated decalcified bone implanted into muscle pouches of animals like rabbits and rats resulted in the formation of new bone and cartilage. This formed the basis of hypothesis of bone formation by autoinduction, in which an inductor cell (a "wandering histiocyte"), acts upon an induced cell (a fixed histiocyte or peri-vascular young connective tissue cell), causing it to differentiate into either an osteoprogenitor or a chondroprogenitor cell. ${ }^{2-5}$

\section{Structure, forms and classification of BMP's}

The members of the TGF- $\beta$ superfamily are derived from precursor polypeptide chains ranging in size from 396-513 amino acids. ${ }^{6}$ Each precursor is made up of an $\mathrm{N}$-terminal secretory leader sequence and a highly conserved C-terminal region containing 114-139 amino acids. ${ }^{7}$ It is the amino acid conservation in the C-terminal region, including a series of seven completely conserved cysteine residues which characterize the members of the TGF- $\beta$ superfamily. An exception to this involves BMP-8, which contains an 8th cysteine in this region?

The mature, active BMP molecule is derived from the carboxy terminus portion of the precursor chain and like other members of the TGF- $\beta$ family, is expected to be in the form of a dimer. These proteins are synthesized as large precursor molecules. After dimerization, these proteins are cleaved proteolytically at a consensus $\mathrm{Arg}-\mathrm{X}-\mathrm{X}$-Arg site to generate mature dimers. It has been shown that the $\mathrm{N}$-terminal region controls the stability of the processed mature protein and that the downstream sequence adjacent to the cleavage site determines the efficiency of cleavage. ${ }^{8}$ Dimers are present in BMP's whose chains are connected by disulfide bonds, and this dimerization is a prerequisite for the induction of bone. BMPs are active in the form of homodimer (two identical chains) as well 
as in the form of heterodimer (two different chains) molecules.

BMP-2 through BMP-8 can be divided into 3 subgroups based on similarities in their amino acid sequences.

\# BMP-2 and BMP-4 form one group, having $92 \%$ amino acid identity within the seven cysteine domain of the mature region.
\# BMP-5 through BMP-8 form a second group, having $82 \%$ identity in this region. These 2 subgroups have $59 \%$ homology with one another, and only $45 \%$ homology with BMP-3, which forms a group by itself. ${ }^{9}$ \# BMP-9 has 50-55\% homology with BMPs 2, 4, 5, 6 and $7 .{ }^{10}$

Mechanism of action bone induction cascade ${ }^{11}$

\begin{tabular}{|c|c|c|}
\hline $\begin{array}{ll}\text { Time } & \text { after } \\
\text { implantation } & \end{array}$ & Cellular events & Molecular processes \\
\hline $1 \mathrm{Min}$ & $\begin{array}{l}\text { Blood clot formation } \\
\text { Platelet release }\end{array}$ & $\begin{array}{l}\text { Fibrin network formation. } \\
\text { Release of platelet derived growth } \\
\text { factors. } \\
\text { Binding of plasma fibronctin to } \\
\text { implanted matrix. }\end{array}$ \\
\hline 1 hour & Arrival of PMN by chemotaxis & $\begin{array}{l}\text { Release of proteolytic enzymes such } \\
\text { as collagenase and elastase }\end{array}$ \\
\hline 18 hours & $\begin{array}{l}\text { Accumulation of PMN's } \\
\text { Adhesion of cells }\end{array}$ & $\begin{array}{l}\text { Limited proteolysis and release of } \\
\text { chemotactic factors for fibroblasts. }\end{array}$ \\
\hline Day 1 & $\begin{array}{l}\text { Chemotaxis of fibroblasts \& Cell } \\
\text { attachment to implanted extra cellular } \\
\text { matrix }\end{array}$ & $\begin{array}{l}\text { Release of peptide of fibronectin } \\
\text { increased cell motility. } \\
\text { Role of microtubules and } \\
\text { microfilaments }\end{array}$ \\
\hline Day 2 & $\begin{array}{l}\text { Chemotaxis for fibroblasts. } \\
\text { matrix to cell surface signal } \\
\text { transduction. }\end{array}$ & $\begin{array}{l}\text { Initiation of protein and nucleic acid } \\
\text { synthesis. } \\
\text { Release of growth factors. }\end{array}$ \\
\hline Day 3 & Cell Proliferation & $\begin{array}{l}\text { Thymidine incorporation into DNA } \\
\text { Increase in ornithine decarboxylase } \\
\text { activity }\end{array}$ \\
\hline Day 5 & Differentiation of chondroblasts & $\begin{array}{l}\text { Increase in } \mathrm{SO}_{4} \text { incorporation into } \\
\text { proteoglycans. }\end{array}$ \\
\hline Day 7 & $\begin{array}{l}\text { Secretion of matrix and synthesis of } \\
\text { chondrocytes }\end{array}$ & $\begin{array}{l}\text { Type II collagen synthesis, cartilage } \\
\text { specific proteoglycans }\end{array}$ \\
\hline Day 9 & $\begin{array}{l}\text { Hypertrophy of chondrocytes } \\
\text { Calcification of cartilage matrix } \\
\text { Vascular invasion }\end{array}$ & $\begin{array}{l}\text { Increase in Ca incorporation and } \\
\text { alkaline phosphatise activity. } \\
\text { Type IV collagen synthesis, Laminin } \\
\text { and factor VIII in blood vessels. }\end{array}$ \\
\hline Day $10-12$ & $\begin{array}{l}\text { Osteoblasts bone formation and } \\
\text { mineralisation }\end{array}$ & $\begin{array}{l}\text { Type I collagen synthesis. } \\
\text { Bone proteoglycans synthesis. } \\
\text { Peak in } \mathrm{Ca} \text { incorporation and alkaline } \\
\text { phosphatise activity. }\end{array}$ \\
\hline Day $12-18$ & $\begin{array}{l}\text { Osteoclasts bone remodelling and } \\
\text { dissolution of implanted matrix. }\end{array}$ & $\begin{array}{l}\text { Increase in lysosomal enzymes. } \\
\text { Upswing in accumulation of y- } \\
\text { carboxyglutamic acid containing } \\
\text { protein. } \\
\text { Release of collagenases and proteases. }\end{array}$ \\
\hline Day 21 & Bone marrow differentiation & $\begin{array}{l}\text { Increase in Fe incorporation into } \\
\text { heme. } \\
\text { Accumulation of lysozyme. } \\
\text { Type III collagen synthesis. }\end{array}$ \\
\hline
\end{tabular}

\section{Biochemical Changes ${ }^{12}$}

a. Mesenchymal cell proliferation on day 3 is quantitated by measuring the amount of $\mathrm{H}$ - thymidine incorporation into cellular DNA and the activity of ornithine decarboxylase in the implant. 
b. Induction of new cartilage is quantitated by sulphate incorporation into cartilage specific proteoglycans and immunpfluroscent localisation of type II collagen.

c. The appearance of bone and the mineralisation of this newly induced bone is indicated by an increase in the specific activity of alkaline phosphatase and $\mathrm{Ca}$ incorporation into bone mineral from day 9 onward.

d. Determing the elevated levels of lysosomal enzymes acd phosphatase and arylsulphatase in day 14 implants monitors bone remodelling.

e. The differentiation of hematopoitic marrow often leads to the increase in the incorporation of iron into heme.

\section{Signalling Pathway}

a. The biological actions of Bone Morphogenetic proteins are mediated via specific Bone Morphogenetic proteins receptors. Bone Morphogenetic proteins receptors are of two typesI and II and are serine/threonine protein kinases.

b. These kinases are the enzymes which are responsible for phosphorylating the proteins called Smads and in turn activate them.

c. The activated Smads are then translocated to the nucleus, where they participate in the transcriptional regulation of the expression of genes which are required in the bone and cartilage formation.

d. There are eight different Smads. Smads 1,5 and 8 are substrates for Bone Morphogenetic proteins receptors.

e. Smads 2 and 3 are substrates for TGF- $\beta$ and activin receptors.

f. Phosphorylation of Smad 1,5 and 8 activates it to interact with common functional partner Smad 4, and this heteromeric complex enters the nucleus to active turn on Bone Morphogenetic proteins responsive genes.

g. There are two inhibitory smads 6 and 7, that normally reside in the nucleus and act as a relay to inhibit or turn off Bone Morphogenetic proteins type I receptor kinase - mediated phosphorylation of Smads 1, 5 and 8.

h. Thus, there is an intricate homeostatic regulation of the Bone Morphogenetic proteins receptor activated turning on genes and their turning off by Smads 6 and 7 through the inhibition of type I Bone Morphogenetic proteins receptor kinase phosphorylation.

i. The BMP signaling cascade, however, is way more complicated than what is described above

\section{Functions of BMP}

\begin{tabular}{|l|l|}
\hline BMP & Function \\
\hline BMP 2 & $\begin{array}{l}\text { Osteoinductive, Osteoblast differentiation, } \\
\text { apotosis }\end{array}$ \\
\hline BMP 3 & Most abundant in bone and inhibits osteogenesis \\
\hline BMP 4 & $\begin{array}{l}\text { Osteoinductive, plays a role in lung and eye } \\
\text { development }\end{array}$ \\
\hline BMP 5 & Helps in Chondrogenesis \\
\hline BMP 6 & $\begin{array}{l}\text { Osteoblast diffentiation and helps in } \\
\text { Chondrogenesis }\end{array}$ \\
\hline BMP 7 & $\begin{array}{l}\text { Osteoinductive. Plays a role in development of } \\
\text { kidney and eye }\end{array}$ \\
\hline BMP 8 & Osteoinductive \\
\hline BMP 9 & $\begin{array}{l}\text { Nervous system, hepatic reticuloendothelial } \\
\text { system development and hepatogenesis }\end{array}$ \\
\hline BMP 10 & Helps in cardiac development \\
\hline BMP 11 & Patterning mesodermal and neuronal tissues \\
\hline BMP 12 & Induces tendon - iliac tissue formation \\
\hline BMP 13 & Induces tendon \& ligament like tissue formation \\
\hline BMP 14 & $\begin{array}{l}\text { Helps in chondrogenesis, enhanves healing and } \\
\text { bone formation }\end{array}$ \\
\hline BMp 15 & Modifies follicle stimulating hormone activity. \\
\hline
\end{tabular}

\section{Carriers}

Bone morphogenetic protein are the water-soluable proteins and have relatively low-molecular weight that diffuses very fast in the body fluids. When administered in a surgical setting, the protein will diffuse very rapidly in wound hematomas or can be irrigated away or lost in the suction drainage, henceforth, it is necessary to contain the BMP. In an experimental setting BMP delivered without a carrier does not endure more than a few hours at the deposited site. It is therefore necessary to contain the BMP in a carrier so 
that it will have a localized effect at the bone healing site. ${ }^{13}$

Collagenous or synthetic matrices have been used as carriers for the BMP's and their physicochemical properties along with the microenvironment they create, play an important role in the induction of bone.

Variety of carriers have been employed. Carriers can be solid xenogenic (HA), solid alloplastic (polyethylene polymers) materials or gels of autogenous, allogenic or alloplastic origin, and combinations of the above.

The main function of the carrier is to maintain the BMP's concentration at the site of implantation and thus enhance its local concentration.However, BMPs also help to stabilize the carrier by accelerating bone growth in its mass due to the stabilization brough about by the BMPs absorption to the surface of the carrier matrix particles. The properties of the carrier however do not affect the pharmacokinetics of the growth factor.

Collagen matrix when used as a carrier has the ability to retain $\sim 65 \%$ of the BMPs during initial impregnation at the bone site and releases it further in two phases : The first one is an initial phase which occurs within hours of the implantation at the bone site and a second phase occurs that depends on the nature of the carrier and its geometrical characteristics. It is believed that BMPs do not bind to the carrier in which it is delivered, but rather become physically entrapped in the structure which makes certain designs more favorable for bone induction over some others.

The ideal properties of the carrier depends upon the specific implantation site and the intended therapeutic outcome. It also depends upon the other factors like biodegradability, structural integrity, absence of immunogenicity, absorption and rate of release of BMP. The latter characteristic of the carrier serves its second function, which is controlled release of the BMP. This ensures a more constant and prolonged application at the bone site. This renders BMPs more efficient and helps to create the chemotactic gradient, necessary for the cells to respond.

Recently, a new approach has been suggested which involves the implanting matrices that actively concentrate native BMPs at the site where they were implanted rather than passively storing and delivering rhBMPs which are a thousand times less potent that the native BMP complex. The matrix also serves as an environment in which bone can form and therefore helps to define the region in which new bone can be formed.

The factors that directly or indirectly affect the bone formation are the material of the matrix and its geometrical parameters (pore size, and \%volume). BMPs combined with porous particles of hydroxyapatite or fibrous collagen membrane lead to intramembranous ossification, whereas fibrous glass membrane or insoluble bone matrix support indirect bone formation via a cartilaginous intermediate.
The carrier may also act by serving as a reservoir of the inducible cell population. Cost of manufacturing and handling, in addition to ease of clinical application, are equally important factors to consider when deciding on a specific type of delivery vehicle.

\section{BMP and bone formation}

Bone formation with the help of BMP's can take place via a direct (intramembranous) or an indirect (endochondral) process.

In the ectopic bone formation which is usually associated with implantation of BMPs at the bone site, the sequence of events recapitulates the entire procedure of bone formation that is seen during the long bone development in an embryo and many of the properties of the BMP's can be extrapolated from there.

One of the most difficult subjects to study with regard to the in vivo response to BMPs is the characterization of the responding cell population. The wide spectrum of cells that are sensitive to BMP action includesfibroblasts, ${ }^{14}$ mesenchymal connective tissue cells, ${ }^{15}$ muscle derived connective tissuecells ${ }^{13}$ and the astroglial lineage. ${ }^{16}$ Bone marrow stromal cells form an important source of mesenchymal pluripotential progenitors that are capable of differentiating into various cell lineages under the appropriate conditions. Demineralized bone matrix, dexamethazone, beta glycerophosphate, vitamin D and BMP-1 have been shown to stimulate bone marrow stromal cells to take on an osteoblastic phenotype.

Bone marrow mesenchymal cells have the potential to differentiate along the osteoblastic and adipocytic lineages. Studies have demonstrated a concentration specific response with lower doses of BMPs inducing the adipocyte lineage and higher doses eliciting a chondrogenic/osteoblastic response. Treatment with rhBMP-2 protects and enhances cell commitment towards the osteoblastic phenotype. Osteoblasts and chondroblasts originate from a common precursor which is a bipotential mesenchymal progenitor called osteo-chondroprogenitor or skeletoblast. Osteoprogenitors can be classified as either determined or inducible, based on their need for additional signals in order to differentiate. This difference is important as it reflects the variation between cell commitment, when the fate of cells is programmed, and cell differentiation, when the fate of cells is expressed due to the permissive signals of the micro-environment. Evidence supports the hypothesis that BMPs act on the skeletal progenitor cells and induce the differentiation of both the osteoblast and chondroblast.

The factors which affect the BMPs ability to induce bone are amounts, qualitative composition, possible presence of inhibitors, correct processing and storage ${ }^{17}$.In addition to the above said factors- the dose, concentration and time of BMP action at the site of implantation are equally important. ${ }^{18}$ Low concentrations of BMP-2 $(50 \mathrm{ng} / \mathrm{ml})$ up-regulated the 
expression of the collagen II gene whereas higher concentrations $(100-400 \mathrm{ng} / \mathrm{ml})$ inhibited collagen II expression in chondrocyte cell lines and increased osteocalcin (OC) expression (72). These results clearly how that chondrocytes are able to express osteoblastic features. It is more realistic to assume that BMPs induce cytodifferentiation along those lineages when permissive conditions for each cell type exist.

The main reason why lose dose of BMP is needed to indice bone formation is primarily due to the differences in the partial pressure oxygen and in the amount of mesenchymal cells present in intramuscular and subcutaneous sites

BMP's induces the differentiation of mesenchymal cells into pre-chondroblasts but the coordinated progression along the chondroblastic and subsequent osteoblastic lineage is regulated by other growth factors that work in an autocrine or paracrine manner. BMPs reduce the expression of collagenase- 3 and noggin through the autocrine mechanism, thereby inhibiting BMP binding and function and results in increased production of collagenase-3. BMPs exert their action on both osteoblasts and chondroblasts, they do not change the fate of the respective progenitors. If the mesenchymal cells are exposed at an early stage to BMPs, it induces the chondroblastic pathway, whereas if they are exposed at a later stage then it accelerates osteoblastic differentiation.

BMPs play a vital role in the process of bone modeling and remodelling and healing. The morphogenetic activity of bone matrix is apparent only after its demineralization, which occurs with the controlled action of osteoclasts.

Insulin-like growth factors (IGF-I, IGF-II), TGF $\beta$ 1, TGF $\beta$ - 2, PDGF, basic and acidic fibroblast growth factors, BMPs and other molecules are produced and become incorporated into the forming bone matrix that serves as a reservoir. BMPs bind to collagen type IV or type I and under these conditions are inactive.

A heparin-binding site has been identified at the $\mathrm{N}$ terminal segments of the BMP-2 that may function to localize the growth factor and restrict itsdiffusion. ${ }^{19}$ Acid treatment associated with osteoclastic action liberates BMPs from their collagenous substrate rendering them biologically active and able to affect cell proliferation and differentiation.

\section{Clinical Applications}

BMPs have a great importance as they act as therapeutic agents for healing the fractures of the bones, prevent osteoporosis of the bone, help in treating periodontal bone defects and enhance the bone response around alloplastic materials implanted in bone. ${ }^{20}$ The augmentation of the maxillary sinus floor in humans has been done successfully using BMP -2 delivered with an absorbable collagen sponge.

Periodontal regeneration was achieved when rhBMP-2 was applied to the defect site with a collagen membrane or a collagen gel. However, better results were obtained using the slower dissolving collagen membrane that allowed delivery of the growth factor for a prolonged period of time. The type of carrier, the time of treatment and the use of a barrier membrane are critical factors influencing the therapeutic outcome in cases of bone regeneration around dental implants and have been shown to produce accelerated healing time as well as improved bone-implant contact levels. ${ }^{20}$

Spinal fusion was significantly enhanced when rhBMP-2 was administered with a hydroxyapatite graft or a collagen gel, anddemineralized bone matrix revealed improved biomechanical properties and enhanced radiographic and histologic appearance.

The biologic potential of many growth factors is further affected by the host age. The higher doses of BMP -2 is required with the advancing age in organisms to induce the bone formation. It has also been seen that theres reduced migration of the mesenchymal cells, lower levels of the local anabolic agents along with the age associated reduction of receptor levels and compromised vascularization.

It has been observed that the combinations of BMPs with other growth factors or biologic molecules which lead to the formation of heterodimers with twenty times higher potency in some cases as compared to the homodimeric forms, hold an exciting future in the field of bioengineering.

\section{Future Trends}

The future clinical investigations and and clinical trials are required to better define the role of BMP's in the bone formation. The dose required, scaffold, route of administration, delivery vehicles, concentration at the local site all play an important role in the final outcome .The impressive results of animal models are difficult to replicate in humans. It is unclear why these differences but the research is on to plug the gap.

One possible answer to this could be the fact that the recruitment of bone precursor cells and bone turnover may occur differently in rodents, small animals and large mammals.

Understanding the regulation between BMPs and BMP-inhibitors might be a key issue. Moreover, different fractures may require different dosages. Critical issues to consider include the potential risk of BMPs inducing heterotopic bone formation, especially when implanted adjacent to neural tissues, and the serious issue of reported antibody formation, noted in up to $38 \%$ of patients in some trials with BMP.

To get the knowledge of BMP usage better, it is important to learn how much dosage is required to produce how much amount of bone because each fracture may require different dosage.

Clearly, the use of BMPs in orthopaedics is still in its early days, but the recent clinical trials in human beings suggest that an exciting and promising future will unfold in the development of novel tissue- 
engineering products for a wide range of clinical situations, with the progressive use of BMPs.

BMP-2 and BMP-7 have been approved by the US Food and Drug Administration (FDA) for specific clinical cases and are delivered in absorbable collagen sponges. Considering the expanding number of publications in the field of BMPs, there are prospects of a brilliant future in the field of regenerative medicine with the use of BMPs.

\section{References}

1. Martinovic S, Simic P Borovecki F, Vukicevic S (2004) Biology of bone morphogenetic proteins. In: S Vukicevic, TK Sampath (eds): Bone morphogenetic proteins: Regeneration of bone and beyond. Birkhauser, Basel, 4573.

2. Urist MR (1965) Bone: Formation by auto-induction, Science 150:893-9.

3. Urist MR, Dowell. Inductive substraction for osteogenesis in pellets of particulate bone matrix. Clin Orthop \& related research 1968, 61,61-78.

4. Urist, M. R, Silverman, B. E, Btiring, K., Dubuc, F. L. \& Rosenberg, J. M, (1967) The bone induction principle. Clinical Orthopaedics and Related Research 53,243- 83

5. Urist, M. R, (1994) The search for and the discovery of bone morphogenetic protein (BMP). In: Bone Grafts. Derivatives and Substitutes, (eds): Urist, M.R., O'Conner, B.T. \& Burwell, R.G., pp. 315-62. London: Butterworth Heinemann.

6. Wozney. J. M. (1994) Molecular biology of the bone morphogenetic proteins. In Bone Grafts.Derivatives and Substitutes, (eds.): Urist, M. R., O'Conner, B. T. \& Burwell, R. G., pp. $397^{\wedge} 13$. London: Butterworth Heinemann.

7. Ripamonti, U. \& Reddi, A. H. (1994) Periodontal regeneration: potential role of bone morphogenetic proteins. Journal of Periodontal Research 29,225-35.

8. Pecina M, Vukicevic S (2007) Biological aspects of bone, cartilage and tendon regeneration. Int Orthop 31;719-20.

9. Wozney, J. M. (1995a) The potential role of bone morphogenetic proteins in periodontal reconstruction. Journal of Periodontology 66, 506-510.

10. Song, J. J, Celeste, A. J, Kong, F M, Jirtie, R. L, Rosen, V \& Thies, R. S. (1995) Bone morphogenetic protein-9 binds to liver cells and stimulates proliferation. Endocrinology 136,4293-7.

11. Reddi AH. Cell biology and biochemistry of endochondral bone development. Cell Rel Res 1981.1;209-26.

12. Alberts, Bruce,Alexander Johnson, Julian Lewis, Martin Raff, Keith Roberts, Peter Walter (2002). Molecular Biology of the Cell. New York, NY: Garland Science. ISBN 0-8153-3218-1.

13. Seeherman H and Wozney JM. 2005; Delivery of bone morphogenetic proteins for orthopaedic tissue regeneration. Cytokine Growth Factor Rev 16:329-45.

14. Runyan CE, Schnaper HW, Poncelet AC (March 2005). "The role of internalization in transforming growth factor beta1-induced Smad2 association with Smad anchor for receptor activation (SARA) and Smad2-dependent signalling in human mesenchymal cells". J. Biol. Chem. 280 (9):8300-8.

15. Moustakas A (September 2002). "Smad signalling network". J. Cell. Sci. 115 (Pt 17):3355-6.

16. Bessa PC, Casal M and Reis RL. Bone morphogenetic proteins in tissue engineering: the road from laboratory to clinic, part II (BMP delivery). J Tissue Eng Regen Med 2008;2:81-96.

17. Ijiri S, Nakamura T, Fujisawa Y, Hazama M \& Komatsudani S. Ectopic bone induction in porous apatite-wollastonite-containing glass ceramic combined with bone morphogenetic protein. Journal of Biomedical Materials Research 199735 421-32.

18. Asahina I,Watanabe M, Sakurai N, Mori M \& Enomoto $\mathrm{S}$. Repair of bone defect in primate mandible using a bone morphogenetic protein (BMP)-hydroxyapatitecollagen composite. Journal of Medical and Dental Sciences $19974463-70$.

19. Reddi, A. H. \& Huggms, C. B. (1973) Influence of geometry of transplanted tooth and bone on transformation of fibroblasts. Proceedings of the Society for Experimental Biology and Medicine 143, 634-7.

20. Reddi AH. 1998; Role of morphogenetic proteins in skeletal tissue engineering and regeneration. Nat Biotechnol 16: 247-52. 